\title{
The Value of C-Reactive Protein, C-Reactive Protein Kinetics and C- reactive Protein to Albumin Ratio on Prognosis in Newly Diagnosed Indolent B-cell Non-Hodgkin Lymphoma
}

\author{
Huimin Zhang \\ Shandong University Affiliated to Shandong University \\ Xiangxiang Zhou \\ Shandong Provincial Hospital Affiliated to Shandong University \\ Xiang Sun \\ Shandong Provincial Hospital Affiliated to Shandong University \\ Yang Han \\ Shandong Provincial Hospital Affiliated to Shandong University \\ Xinting $\mathrm{Hu}$ \\ Shandong Provincial Hospital Affiliated to Shandong University \\ Xiaoya Yun \\ Shandong University Affiliated to Shandong University \\ Ya Zhang \\ Shandong Provincial Hospital Affiliated to Shandong University \\ Xin Wang ( $\checkmark$ xinw007@126.com ) \\ Shandong Provincial hospital affiliated to Shandong University
}

\section{Research}

Keywords: indolent B-cell non-Hodgkin lymphoma, C-reactive protein, Kinetics, Albumin, Prognosis

Posted Date: November 12th, 2020

DOI: https://doi.org/10.21203/rs.3.rs-103728/v1

License: (c) (i) This work is licensed under a Creative Commons Attribution 4.0 International License. Read Full License 


\section{Abstract}

Objective: This study aimed to determine prognostic significance of C-reactive protein (CRP), CRP kinetics and CRP to albumin ratio (CAR) in indolent B-cell non-Hodgkin lymphoma (B-iNHL) patients.

Methods: The association among these blood makers and overall survival (OS), disease-free survival (DFS), progression-free survival (PFS) were analyzed in $243 \mathrm{~B}$-iNHL patients. OS, DFS and PFS were determined by Kaplan-Meier curves. Cox proportional analysis was performed to examine the prognostic significance of clinicopathological variables.

Results: Multivariate analyses identified that elevated pretreatment CRP (HR: 5.110, 95\% Cl: 1.904-13.717, p=0.001), post-treatment CRP (HR: 5.826, 95\% Cl: 1.659-20.458, $p=0.006)$, continuously elevated CRP (HR: 6.461, 95\% Cl: 2.620-15.930, p<0.001) and elevated CAR (HR: 3.768, 95\% Cl: 1.415$10.034, p=0.008)$ had association with worse OS. Likewise, elevated pretreatment CRP (HR: $3.767,95 \%$ Cl: 1.777-7.984, $p=0.001)$, post-treatment CRP (HR: 2.384, 95\% Cl: 1.027-5.534, $p=0.043$ ), ever-elevated CRP (HR: 2.425, 95\% Cl: 1.105-5.322, $p=0.027$ ), continuously elevated CRP (HR: 4.748, 95\% Cl: 2.114-10.660, $p<0.001)$ and elevated CAR (HR: 2.824, 95\% Cl: 1.336-5.971, $p=0.007$ ) were in independent significance with worse DFS. Elevated pretreatment CRP (HR: 2.606, 95\% Cl: 1.338-5.076, $p=0.005)$, ever-elevated CRP (HR: 2.086, 95\% Cl: 1.040-4.188, $p=0.039$ ), continuously elevated CRP (HR: 3.296, 95\% Cl: 1.594-6.818, $p=0.001$ ) and elevated CAR (HR: 1.991, 95\% Cl: 1.021-3.882, $p=0.043$ ) were determined in independent significance with poor PFS. The effect was statistically significant in both follicular lymphoma (FL) and chronic lymphocytic leukemia/ small lymphocytic lymphoma (CLL/ SLL) patients.

Conclusions: In conclusion, we demonstrate that CRP level, CRP kinetics and CAR could be potential prognostic indicators with independent significance in patients with B-iNHL, also in FL and CLL/ SLL subgroups. CRP and CAR make an implementation for prognostic evaluation more easily and effectively in B-iNHL patients.

\section{Introduction}

Indolent B-cell non-Hodgkin lymphoma (B-iNHL) are collection of malignancies, which are characterized by slow growth that can be alleviated with treatment but cannot be cured [1]. The main subtypes include follicular lymphoma (FL), marginal zone lymphoma (MZL), chronic lymphocytic leukemia/ small lymphocytic lymphoma (CLL/ SLL) and lymphoplasmacytic lymphoma/ Waldenstroms macroglobulinemia (LPL/ WM). Disease progress or relapse is never desirable, but progress, relapse and retreatment occur on some B-iNHL patients. Early identification of these patients is of great significance for their treatment. However, limitations of existing risk stratification tools in routine clinical use exist, it is urgent to find new prognostic predictors. Thus, a series of studies had been carried out to search for effective alternative prognostic biomarkers [2-5].

The association between inflammation and tumors has been early presented [6]. C-reactive protein (CRP), a biomarker compounded in hepatic cells induced by pro-inflammatory cytokines, is the most commonly used clinical indicator of inflammation [7-9]. According to previous research, high CRP level is considered a dangerous factor for cardiovascular diseases, diabetes and chronic hepatitis B virus (HBV) inflammatory [10-14]. A number of previous studies have shown that elevated CRP level was associated with poor outcome in rectal cancer, hepatocellular carcinoma, lung carcinoma, melanoma, bone neoplasms, breast cancer, ovarian cancer, esophageal carcinoma and other solid tumors [15-23]. Regarding to hematological cancers, elevated CRP level has been reported as a poor prognostic predictor in diffuse large B-cell lymphoma, angioimmunoblastic T-cell lymphoma and CLL [24-26]. In addition, the prognostic value of CRP kinetics, dynamic change of CRP level throughout treatment, has been confirmed in metastatic nasopharyngeal carcinoma and renal cell carcinoma [27-29]. Furthermore, a novel prognostic markers involving inflammation and nutrition, CRP to albumin ratio (CAR), has been evaluated in colorectal cancer, liver cell carcinoma, lung cancer, and other solid tumors [30-34]. The prognostic significance of CRP level, CRP kinetics and CAR in B-iNHL are unclear.

This study aimed to investigate whether CRP level, CRP kinetics and CAR were potential prognostic indicators in B-iNHL patients. We studied the association among pretreatment CRP level, CRP level during treatment, post-treatment CRP level, CRP kinetics, pretreatment CAR and overall survival (OS), disease-free survival (DFS), progression-free survival (PFS). Furthermore, prognostic significance of CRP level, CRP kinetics and CAR in the different subgroups diseases also were investigated.

\section{Materials And Methods}

\section{Patients}

Patients who were diagnosed with B-iNHL according to the 2008 WHO classification and 2016 WHO classification between January 2012 and December 2019 at the Shandong provincial hospital in China were involved in this study [35-36]. The following types of disease were included in our analysis: FL, MZL, CLL/ SLL and LPL/ WM. Patients who were diagnosed with grade 3b FL, non-newly diagnosed, with other hematological cancers combined and had not any CRP or albumin record were excluded.

\section{Clinical data}


All clinicopathological data were obtained from medical records. Clinicopathological parameters included histologically confirmed B-iNHL, gender, age, clinical stage, international prognostic index (IPI) and treatment plan. Rai staging system was used for the clinical stage of CLL/ SLL and Ann Arbor staging system was used for FL, MZL and LPL/ WM. Laboratory data, including hemoglobin (Hb), platelet count (PLT), lactate dehydrogenase $(\mathrm{LDH})$ and $\beta 2$-microglobulin ( $\beta 2-\mathrm{MG})$, were obtained ahead of treatment.

\section{Follow-up}

Patients were followed up each month during complete chemotherapy cycle, every 3 months after treatment first 2 years and semiyearly thereafter. Information of death or relapse were known by referring to clinical cases or calling to their relatives for ask. OS referred to the time (in months) from diagnosis to death from any cause. DFS referred to the time (in months) from diagnosis to the palindromia of the disease being confirmed histologically or death due to disease. PFS referred to the time (in months) from diagnosis to the progression of the disease or death due to disease. This study was approved by the Biomedical Research Ethic Committee of Shandong province hospital (NO. SWYX2020-027) and informed consent was exempted based on medical records involved in this study obtained in previous clinical diagnosis and treatment.

\section{CRP level, CRP kinetics and albumin}

Serum level of CRP were obtained at baseline (pretreatment CRP level), ahead of each chemotherapy (CRP level during treatment) and after all consecutive chemotherapy (post-treatment CRP level). The data were considered missing if the patient was suffering acute infection or acute episode of chronic infection. Furthermore, patients were divided into 3 cohorts based on CRP kinetics: i) continuously normal cohort: patients' CRP level were normal all the time, ii) ever-elevated cohort: patients' CRP level were ever elevated regardless any time point, iii) continuously elevated cohort: patients' CRP level were elevated all the time. In addition, serum level of albumin was obtained ahead of treatment.

\section{Statistical analyses}

First of all, receiver operating curve (ROC) analysis was used to determine the optimal cutoff value for pretreatment CRP level and CAR to distinguish between living and dead. The association between CRP level, CRP kinetics, CAR and clinicopathological parameters were evaluated by chi-square test. The association between CRP level, CRP kinetics, CAR and OS, DFS or PFS were determined by Kaplan-Meier curves and log-rank test. The significance of clinicopathological variables were confirmed by Cox proportional analysis in univariate and multivariate analyses. Hazard ratios (HRs) with corresponding $95 \%$ confidence intervals (Cls) were reported as relative risks. All statistical analyses were performed using IBM SPSS Statistics, Version 26. A two-sided $P<0.05$ was considered statistically significant.

\section{Results}

\section{Patient characteristics}

Overall, a total of 377 B-iNHL patients, including FL, MZL, CLL/ SLL and LPL/WM, were diagnosed and treated during the January 2012 and December 2019 at our center. Patients who were diagnosed with grade $3 b \mathrm{FL}(\mathrm{n}=9)$, non-newly diagnosed $(n=44)$, with other hematological cancers combined ( $n=3$ ) and had not any CRP or albumin record ( $n=78)$ were excluded. Finally, 243 patients, including FL ( $n=77), M Z L$ ( $n=46)$, CLL/ SLL $(n=91)$ and LPL/ WM $(n=29)$, were found to meet study criteria and were involved in the analysis. The median age at diagnosis was 59 (range 19 85) years, with 133 (54.7\%) males, and 110 (45.3\%) females. The median follow-up time was 23 (range,1-83) months. 31 (12.8\%) patients died, 45 (18.5\%) patients had disease recurrence or died due to disease and 51 (21.3\%) patients suffered disease progression or died due to disease by their most recent follow-up visit. (Table 1).

\section{Serum CRP level and CAR cutoff selection}

An optimal pretreatment CRP level cutoff value was determined by ROC analysis (area under the curve: $0.747,95 \%$ Cl: $0.631-0.894$, specificity: 0.739 , sensitivity: $0.739, p<0.001$ ) (Figure $1 \mathrm{~A}$ ). This cutoff was $5.84 \mathrm{mg} / \mathrm{L}$, also used in other time CRP level cohorts. Similarly, the optimal cutoff value of pretreatment CAR was 0.117 (area under the curve: $0.753,95 \% \mathrm{Cl}$ : $0.634-0.872$, specificity: 0.687 , sensitivity: $0.783, p<0.001$ ) (Figure $1 \mathrm{~B}$ ).

\section{Association of CRP level, CRP kinetics and CAR with clinicopathological features}

Pretreatment elevated CRP level was significantly correlated with clinical stage, reduced Hb level, high LDH level, elevated $\beta 2-\mathrm{MG}$ level, disease types, IPI and treatment plan $(p<0.05)$. The correlation between post-treatment elevated CRP level and age, reduced $\mathrm{Hb}$ level and disease types were observed $(p<0.05)$. CRP kinetics was significantly correlated with age, clinical stage, reduced $\mathrm{Hb}$ level, elevated $\beta 2-\mathrm{MG}$ level, disease types, IPI and treatment plan $(p<0.05)$. Likewise, the correlation between CAR and clinical stage, reduced Hb level, elevated $\beta 2-\mathrm{MG}$ level, disease types, IPI and treatment plan were observed $(p<0.05)$. (Table1).

\section{Prognostic value of pretreatment CRP level}

Within the cohort of 243 patients, 222 had pretreatment CRP level record. Poor five-year OS ( $94.3 \%$ vs. 56.7\%, $p<0.001$, log-rank test), DFS (88.0\% vs. $33.9 \%, p<0.001$, log-rank test) and PFS (78.3\% vs. $40.6 \%, p<0.001$, log-rank test) could be determined among patients whose pretreatment CRP level 
were elevated (Figure 2A-C).

Univariate Cox proportional analysis identified that pretreatment elevated CRP level was prognosticator for patients' worse 0S (HR: 6.546, 95\% Cl: 2.543-16.853, $p<0.001$ ), DFS (HR: 4.704, 95\% Cl: 2.305-9.601, $p<0.001$ ) and PFS (HR: 3.177, 95\% Cl: 1.694-5.961, $p<0.001$ ). For the multivariate analyses, in line with the recommended ratio of $\geq 5-9$ events per variable, four variables, including pretreatment CRP level, clinical stage, PLT and B2-MG, was performed [37]. Since these four variables showed larger HR in the univariate model. We identified pretreatment elevated CRP level (HR: 5.110, 95\% Cl: 1.904-13.717, $p=0.001)$ and reduced PLT (HR: 3.994, 95\% Cl: 1.635-9.754, $p=0.002)$ as independent predictors for 0S. Simultaneously, we also identified pretreatment elevated CRP level (HR: 3.767, 95\% Cl: 1.777-7.984, $p=0.001$ ), and reduced PLT (HR: 2.320, 95\% Cl: 1.071-5.023, $p=0.033)$ were independent prognostic predictors for DFS. As well as, increased pretreatment elevated CRP level (HR: 2.606, 95\% Cl: 1.338-5.076, $p=0.005$ ) was proved predicting independently patients' poor PFS. (Table 2).

\section{Prognostic value of CRP level during treatment}

In our study, elevated CRP level during treatment was not associated with five-year OS (89.7\% vs. $82.4 \%, p=0.924$, log-rank test), DFS (81.7\% vs. $56.6 \%, p=0.378$, log-rank test) and PFS (69.4\% vs. 55.5\%, $p=0.586$, log-rank test) (Figure 2D-F). Thus, univariate and multivariate Cox proportional analyses were not carried out among these patients.

\section{Prognostic value of post-treatment CRP level}

To evaluate the prognostic significance of post-treatment CRP level, 64 of 243 patients who had post-treatment CRP level record were involved in the analysis. Negative prognostic value of post-treatment elevated CRP level for five-year OS (81.7\% vs. 39.4\%, $p<0.001$, log-rank test) (Figure 2G) and DFS (56.4\% vs.35.7\%, $p=0.020$, log-rank test) (Figure $2 \mathrm{H}$ ) could also be found. However, elevated post-treatment CRP level was not associated with five-year PFS ( $49.8 \%$ vs. $38.8 \%, p=0.058$, log-rank test) (Figure $2 \mathrm{l}$ ). So we just carried out univariate and multivariate Cox regression analyses of the main prognostic factors for OS and DFS in post-treatment CRP level subgroup.

Univariate Cox proportional analysis identified post-treatment elevated CRP level were associated with patients' worse OS (HR: 6.728, 95\% Cl: 2.01522.465, $p=0.002$ ) and DFS (HR: 2.601, 95\% Cl: 1.126-6.008, $p=0.025)$. As post-treatment CRP level, PLT and $\beta 2-\mathrm{MG}$ showed the larger HR in the univariate model, they were involved in the multivariate analyses. We found post-treatment elevated CRP level (HR: $5.826,95 \% \mathrm{Cl}$ : $1.659-20.458$, $p=0.006)$ and reduced PLT (HR: 8.532, 95\% Cl: 2.065-35.241, $p=0.003$ ) independently predicted patients' poor OS. In addition, we identified posttreatment elevated CRP level (HR: 2.384, 95\% Cl: 1.027-5.534, $p=0.043$ ) was independent predictor for DFS. (Table 3).

\section{Prognostic value of CRP kinetics}

Among 243 patients, highly significant association between CRP kinetics and poor five-year OS (80.0\% vs. $82.8 \%$ vs. $47.1 \%, p<0.001$, log-rank test), DFS $(80.2 \%$ vs. $62.9 \%$ vs. $35.3 \%, p<0.001$, log-rank test) and PFS ( $72.4 \%$ vs. $61.9 \%$ vs. $41.9 \%, p<0.001$, log-rank test) could be found (Figure $2 \mathrm{~J}-\mathrm{L})$.

Univariate Cox proportional analysis identified continuously elevated CRP level as prognosticator for patients' worse OS (HR: 6.661, 95\% Cl: 2.77515.988, $p<0.001$ ). Ever-elevated CRP level (HR: 3.483, 95\% Cl: 1.615-7.511, $p=0.001$ for DFS and HR: 2.638, 95\% Cl: 1.346-5.173, $p=0.005$ for PFS) and continuously elevated CRP level (HR: 5.232, 95\% Cl: 2.356-11.622, $p<0.001$ for DFS and HR: 3.663, 95\% Cl: 1.790-7.496, $p<0.001$ for PFS) were significantly associated with patients' poor DFS and PFS. Multivariate analyses, including CRP kinetics, clinical stage, PLT and $\beta 2-M G$ were performed. We identified continuously elevated CRP level (HR: 6.461, 95\% Cl: 2.620-15.930, $p<0.001$ ) and reduced PLT (HR: 4.025, 95\% Cl: 1.7919.049, $p=0.001)$ could independently predict patients' poor OS. What's more, ever-elevated CRP level (HR: 2.425, 95\% Cl: 1.105-5.322, $p=0.027)$, continuously elevated CRP level (HR: 4.748, 95\% Cl: 2.114-10.660, $p<0.001)$ and elevated $\beta 2-\mathrm{MG}$ level (HR: 2.100, 95\% Cl: 1.036-4.255, $p=0.039)$ were found as independent predictors for DFS. Ever-elevated CRP level (HR: 2.086, 95\% Cl: 1.040-4.188, $p=0.039)$ and continuously elevated CRP level (HR: 3.296, 95\% Cl: 1.594-6.818, $p=0.001$ ) also were found as independent predictors for PFS. (Table 4).

\section{Prognostic value of pretreatment CAR}

Within the cohort of 243 patients, 221 patients had pretreatment CAR record. Poor five-year OS (93.1\% vs. 61.9\%, $p<0.001$, log-rank test), DFS (87.3\% vs. $42.8 \%, p<0.001$, log-rank test) and PFS (77.2\% vs. $48.8 \%, p=0.002$, log-rank test) could be determined among these patients whose CAR were high (Figure 2M-O).

Univariate Cox proportional analysis identified pretreatment CAR were associated with patients' poor OS (HR: 5.426, 95\% Cl: 2.018-13.962, p<0.001), DFS (HR: 3.856, 95\% Cl: 1.888-7.874, $p<0.001$ ) and PFS (HR: 2.591, 95\% Cl: 1.381-4.858, $p=0.003$ ). For the multivariate analyses, four variables, including pretreatment CAR, clinical stage, PLT and $\beta 2-\mathrm{MG}$, were performed. We identified pretreatment CAR (HR: 3.768, 95\% Cl: 1.415-10.034, $p=0.008)$ and reduced PLT (HR: 3.475, 95\% Cl: 1.439-8.394, $p=0.006)$ independently predicted poor OS. Simultaneously, pretreatment CAR (HR: 2.824, 95\% Cl: $1.336-5.971, p=0.007$ for DFS and HR: $1.991,95 \% \mathrm{Cl}: 1.021-3.882, p=0.043$ for PFS) also was independent predictors for DFS and PFS. (Table 5).

Prognostic significance of CRP level, CRP kinetics and pretreatment CAR in the different diseases subgroups 
Highly significant association between CRP level, CRP kinetics, CAR and poor OS, DFS, PFS ( $p<0.05$, log-rank test) could be determined in CLL/ SLL subgroup. In FL cohort, a negative prognostic value of pretreatment elevated CRP level, CRP kinetics and CAR for OS, DFS, PFS ( $p<0.05$, log-rank test) could be identified. However, elevated post-treatment CRP level was not associated with OS and DFS in FL cohorts. Furthermore, elevated CRP level, CRP kinetics and CAR were not associated with OS, DFS and PFS in MZL and LPL/ WM subgroups. (Table 6).

\section{Discussion}

The present study is the first research to investigate the prognostic value of CRP level, CRP kinetics and CAR in B-iNHL patients.

The reason for elevated CRP level associated with worse prognosis among cancer patients remains unknown. Previous studies had shown that inflammatory may contribute directly to tumor progression [38-39]. Zhao Sun et al. demonstrated that tumors cause inflammation, and inflammatory tumor microenvironments recruit mesenchymal stem cells (MSCs) [40]. These MSCs promote tumor growth, progression, and metastasis, leading to the formation of a vicious cycle. Inflammation has also been reported promoting development and progression of cholangiocarcinoma and hepatocellular carcinoma [41-43]. IL-6, as the main inducers of CRP synthesis, was proved promote the progression of cholangiocarcinoma and other cancers [44-47]. Moreover, Yang et al. confirmed that CRP promoted myeloma cell proliferation under stress and protected cancer cells from being damaged by chemotherapy drugs [48]. What's more, Shengchao Xu et al. demonstrated that inflammasome inhibitors are helpful in the treatment of inflammation-related tumors [49]. Clearly, the mechanisms of CRP regarding the progression of B-iNHL need to be clarified in further investigations.

Fairclough et al. firstly presented the conception of CAR in 2009 [50]. Because of too much energy expenditure, cancer patients often suffer malnutrition. Because of increased catabolism and the reduce of hepatic synthesis, albumin is oppositely associated with inflammatory [51]. CAR is a novel and superior prognostic factor involving inflammatory and nutritional factors in various cancers, which was also confirmed in B-iNHL patients. CRP and albumin are routinely tested in most hospital, which make an implementation for prognostic evaluation more easily and effectively in B-iNHL patients.

In the stratified analyses, post-treatment elevated CRP level was considered to be not associated with PFS. This may be due to the fact that fewer patients have a record of post-treatment CRP and the cutoff value was no best distinction between progressive and non-progressive patients. In addition, post-treatment elevated CRP level was considered to be not associated with OS and DFS in FL cohort. This may be attributed to a reduced level of positive events. Besides, negative results were reported in MZL and LPL/ WM cohorts. The reason may be related to the small number of patients included in these cohorts.

Our study has some limitations. Patients with B-iNHL were recruited from a same hospital and might not be representative of the general B-iNHL. CRP is a non-specific biomarker of inflammation. It is possible that patient's infection status was not recorded in the case, which affected the exclusion of data. Other potential cofounders of CRP level, including body mass index, smoking and systemic treatment variables, were not included in our study.

\section{Conclusions}

We demonstrated pretreatment and post-treatment elevated CRP level can independently predict poor clinical outcomes in patients with B-iNHL. The study of CRP kinetics shows that ever and continuously and ever elevated CRP level indicate unfavorable prognosis for B-iNHL. Furthermore, pretreatment CAR as independent poor prognostic factor for clinical outcomes also were confirmed. Further investigations including large prospective studies were required to determine optimal CRP level and CAR value and to improve body inflammatory response to the malignancies.

\section{Abbreviations}

CRP C-reactive protein

CAR C-reactive protein to albumin ratio

B-iNHL indolent B-cell non-Hodgkin lymphoma

OS overall survival

DFS disease-free survival

PFS progression-free survival

FL follicular lymphoma

MZL marginal zone lymphoma 
CLL/ SLL chronic lymphocytic leukemia/ small lymphocytic lymphoma

LPL/ WM lymphoplasmacytic lymphoma/ Waldenstroms macroglobulinemia

HBV hepatitis B virus

IPI international prognostic index

$\mathrm{Hb}$ hemoglobin

PLT platelet count

LDH lactate dehydrogenase

ß2-MG $\beta 2$-microglobulin

ROC receiver operating curve

HR Hazard ratio

$\mathrm{Cl}$ confidence interval

MSCs mesenchymal stem cells

R-CHOP rituximab, cyclophosphamide, doxorubicin, vincristine, and prednisone

R-FC rituximab, fludarabine and cyclophosphamide

\section{Declarations}

\section{Ethics approval and consent to participate}

This study was approved by the Biomedical Research Ethic Committee of Shandong province hospital (NO. SWYX2020-027) and informed consent was exempted based on medical records involved in this study obtained in previous clinical diagnosis and treatment.

\section{Consent for publication}

All of the authors review the manuscript and consent for publication.

\section{Availability of data and materials}

The datasets used and/or analysed during the current study are available from the corresponding author on reasonable request.

\section{Competing interests}

The authors declare that they have no competing interests.

\section{Funding}

This study was funded by National Natural Science Foundation (No. 81270598, No. 81473486, No. 81770210 and No. 82000195 );Key Research and Development Program of Shandong Province (No. 2018CXGC1213); Technology Development Projects of Shandong Province (No. 2017GSF18189); Taishan Scholars Program of Shandong Province; Shandong Provincial Engineering Research Center of Lymphoma; Key Laboratory for Kidney

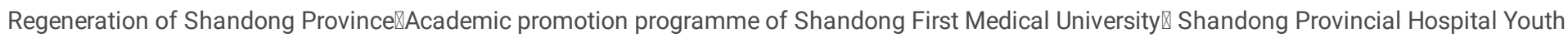
Talent Plan; Shandong Provincial Hospital Research Incubation Fund.

\section{Authors' contributions}

Huimin Zhang, investigation, data curation, statistic analysis, writing-original draft preparation; Xiangxiang Zhou, Xiang Sun, Yang Han, Xinting Hu and Xiaoya Yun, investigation, data curation; Ya Zhang, funding acquisition, writing-review and editing; Xin Wang, project administration, funding acquisition, writing-review and editing.

\section{Acknowledgements}

This study was funded by National Natural Science Foundation (No. 81270598, No. 81473486, No. 81770210 and No. 82000195 );Key Research and Development Program of Shandong Province (No. 2018CXGC1213); Technology Development Projects of Shandong Province (No. 2017GSF18189); 
Taishan Scholars Program of Shandong Province; Shandong Provincial Engineering Research Center of Lymphoma; Key Laboratory for Kidney Regeneration of Shandong Province $₫$ Academic promotion programme of Shandong First Medical University $₫$ Shandong Provincial Hospital Youth Talent Plan; Shandong Provincial Hospital Research Incubation Fund.

\section{References}

1. Armitage JO, Gascoyne RD, Lunning MA, Cavalli F. Non-Hodgkin lymphoma. Lancet. 2017;390(10091):298-310. doi: 10.1016/S01406736(16)32407-2.

2. Yun $X Y$, Zhang Y, Wang X. Recent progress of prognostic biomarkers and risk scoring systems in chronic lymphocytic leukemia. Biomark Res. 2020;8:40. doi: 10.1186/s40364-020-00222-3.

3. Yang G, Mills M, Kim Y, Figura NB, Doyle C, Oliver D, Grass GD, Robinson T, Chavez J, Kim S. Enhancement of the Follicular Lymphoma International Prognostic Index (FLIPI) with lymphopenia (FLIPI-L): a predictor for overall survival and histologic transformation. Blood Cancer J. 2020;9(12):104. doi: 10.1038/s41408-019-0269-6.

4. Domínguez-Berrocal L, Zhang X, Zini JM, Fominaya J, Rebollo A, Bravo J. Evaluation of Caspase-9b and PP2Aca2 as potential biomarkers for chronic lymphocytic leukemia. Biomark Res. 2016;4:9. doi: 10.1186/s40364-016-0063-6.

5. Arribas Arranz J, Winter DN, Drexler HG, Eberth S. Suitability of Yin Yang 1 transcript and protein levels for biomarker studies in B cell nonHodgkin lymphoma. Biomark Res. 2018;6:11. doi: 10.1186/s40364-018-0126-y.

6. Coussens LM, Werb Z. Inflammation and cancer. Nature. 2002;420(6917):860-867. doi: 10.1038/nature01322.

7. Tillet WS, Francis T. Serological reactions in pneumonia with a non-protein somatic fraction of Pneumococcus. J Exp Med. 1930;52(4):561571. doi: 10.1084/jem.52.4.561.

8. Weinhold B, Bader A, Poli V, Rüther U. Interleukin-6 is necessary, but not sufficient, for induction of the human C-reactive protein gene in vivo. Biochem J. 1997;1;325(Pt 3)(Pt 3):617-21. doi: 10.1042/bj3250617.

9. Boras E, Slevin M, Alexander MY, Aljohi A, Gilmore W, Ashworth J, Krupinski J, Potempa LA, Al Abdulkareem I, Elobeid A, et al. Monomeric Creactive protein and Notch-3 co-operatively increase angiogenesis through PI3K signalling pathway. Cytokine. 2014;69(2):165-179. doi: 10.1016/j.cyto.2014.05.027.

10. Boncler M, Wu Y, Watala C. The Multiple Faces of C-Reactive Protein-Physiological and Pathophysiological Implications in Cardiovascular Disease. Molecules. 2019;24(11):2062. doi: 10.3390/molecules24112062.

11. Avan A, Tavakoly Sany SB, Ghayour-Mobarhan M, Rahimi HR, Tajfard M, Ferns G. SerumC-reactive protein in the prediction of cardiovascular diseases: overview of the latest clinical studies and public health practice. J Cell Physiol. 2018;233(11):8508-8525. doi: 10.1002/jcp.26791.

12. Liu C, Feng X, Li Q, Wang Y, Li Q, Hua M. Adiponectin, TNF-alpha and inflammatory cytokines and risk of type 2 diabetes: a systematic review and meta-analysis. Cytokine. 2016;86:100-109. doi: 10.1016/j.cyto.2016.06.028.

13. Jeong H, Baek SY, Kim SW, Park EJ, Lee J, Kim H, Jeon CH. C reactive protein level as a marker for dyslipidaemia, diabetes and metabolic syndrome: results from the Korea National Health and Nutrition Examination Survey. BMJ Open. 2019;9(8):e029861. doi: 10.1136/bmjopen2019-029861.

14. Zhu S, Waili Y, Qi X, Chen Y, Lou Y, Chen B. Serum C-reactive protein predicts early mortality in hospitalized patients with HBV-related decompensated cirrhosis. Medicine (Baltimore). 2017;96(4):e5988. doi: 10.1097/MD.0000000000005988.

15. Lin ZY, Liang ZX, Zhuang PL, Chen JW, Cao Y, Yan LX, Yun JP, Xie D, Cai MY. Intrahepatic cholangiocarcinoma prognostic determination using pre-operative serum C-reactive protein levels. BMC Cancer. 2016;16(1):792. doi: 10.1186/s12885-016-2827-7.

16. Li W, Luo X, Liu Z, Chen Y, Li Z. Prognostic value of C-reactive protein levels in patients with bone neoplasms: A meta-analysis. PLoS One. 2018;13(4):e0195769. doi: 10.1371/journal.pone.0195769.

17. Yoshida T, Ichikawa J, Giuroiu I, Laino AS, Hao Y, Krogsgaard M, Vassallo M, Woods DM, Stephen Hodi F, Weber J. C reactive protein impairs adaptive immunity in immune cells of patients with melanoma. J Immunother Cancer. 2020;8(1):e000234. doi: 10.1136/jitc-2019-000234.

18. Meischl T, Rasoul-Rockenschaub S, Györi G, Sieghart W, Reiberger T, Trauner M, Soliman T, Berlakovich G, Pinter M. Tobias Meischl, Susanne Rasoul-Rockenschaub, Georg Györi, Wolfgang Sieghart, Thomas Reiberger, Michael Trauner. C-reactive protein is an independent predictor for hepatocellular carcinoma recurrence after liver transplantation. PLoS One. 2019;14(5):e0216677. doi: 10.1371/journal.pone.0216677.

19. Wang Y, Zhang Z, Wang J, Zhang X. Association between C-reactive protein level and subsequent risk of ovarian cancer: A meta-analysis of 13 cohorts in 1,852 ovarian cancer patients. Medicine (Baltimore). 2020;99(5):e18821. doi: 10.1097/MD.0000000000018821.

20. Huang W, Wu L, Liu X, Long H, Rong T, Ma G. Preoperative serum C-reactive protein levels and postoperative survival in patients with esophageal squamous cell carcinoma: a propensity score matching analysis. J Cardiothorac Surg. 2019;14(1):167. doi: 10.1186/s13019-0190981-0.

21. Xiao X, Wang S, Long G. C-reactive protein is a significant predictor of improved survival in patients with advanced non-small cell lung cancer. Medicine (Baltimore). 2019;98(26):e16238. doi: 10.1097/MD.0000000000016238. 
22. Schimmack S, Yang Y, Felix K, Herbst M, Li Y, Schenk M, Bergmann F, Hackert T, Strobel O. Simon Schimmack, et al. C-reactive protein (CRP) promotes malignant properties in pancreatic neuroendocrine neoplasms. Endocr Connect. 2019;8(7):1007-1019. doi: 10.1530/EC-19-0132.

23. Lee E, Nelson OL, Puyana C, Takita C, Wright JL, Zhao W, Reis IM, Lin RY, Hlaing WWM, Bakalar JL, et al. Association between C-reactive protein and radiotherapy-related pain in a tri-racial/ethnic population of breast cancer patients: a prospective cohort study. Breast Cancer Res. 2019;21:70. doi: 10.1186/s13058-019-1151-y.

24. Troppan KT, Schlick K, Deutsch A, Melchardt T, Egle A, Stojakovic T, Beham-Schmid C, Weiss L, Neureiter D, Wenzl K, et al. C-reactive protein level is a prognostic indicator for survival and improves the predictive ability of the R-IPI score in diffuse large B-cell lymphoma patients. Br $\mathrm{J}$ Cancer. 2014;111(1):55-60. doi: 10.1038/bjc.2014.277.

25. Li Y, Yang C, Mao L, Wang J, Li C, Qian W. Ying Li, Chunmei Yang, Liping Mao, Jinghan Wang, Chenying Li, Wenbin Qian. Clinical characteristics of angioimmunoblastic T-cell lymphoma in China and C-reactive protein as an independent prognostic factor. Medicine (Baltimore). 2017;96(39):e8091. doi: 10.1097/MD.0000000000008091.

26. Herishanu Y, Polliack A, Shenhar-Tsarfaty S, Weinberger R, Gelman R, Ziv-Baran T, Zeltser D, Shapira I, Berliner S, Rogowski O. Increased serum C-reactive protein levels are associated with shorter survival and development of second cancers in chronic lymphocytic leukemia. Ann Med. 2017;49(1):75-82. doi:10.1080/07853890.2016.1232860.

27. Chen R, Zhou Y, Yuan Y, Zhang Q, He S, Chen Y, Ren Y. Ruiwan Chen, et al. Effect of CRP and Kinetics of CRP in Prognosis of Nasopharyngeal Carcinoma. Front Oncol. 2019;9:89. doi: 10.3389/fonc.2019.00089.

28. Xia WX, Ye YF, Lu X, Wang L, Ke LR, Zhang HB, Roycik MD, Yang J, Shi JL, Cao KJ, et al. The Impact of Baseline Serum C-Reactive Protein and C-Reactive Protein Kinetics on the Prognosis of Metastatic Nasopharyngeal Carcinoma Patients Treated with Palliative Chemotherapy. PLoS One. 2013;8(10):e76958. doi: 10.1371/journal.pone.0076958.

29. Fujita T, Tabata KI, Ishii D, Matsumoto K, Yoshida K, Iwamura M. Prognostic effect of serum C-reactive protein kinetics on advanced renal cell carcinoma treated with sunitinib. Mol Clin Oncol. 2017;6(5):691-696. doi: 10.3892/mco.2017.1201.

30. Zhou QP, Li XJ. C-Reactive Protein to Albumin Ratio in Colorectal Cancer: A Meta-Analysis of Prognostic Value. Dose Response. 2019;17(4):1559325819889814. doi: 10.1177/1559325819889814.

31. Yang JR, Xu JY, Chen GC, Yu N, Yang J, Zeng DX, Gu MJ, Li DP, Zhang YS, Qin LQ. Post-diagnostic C-reactive protein and albumin predict survival in Chinese patients with non-small cell lung cancer: a prospective cohort study. Sci Rep. 2019;9:8143. doi: 10.1038/s41598-019-44653$\mathrm{x}$.

32. Zhou L, Ma S, Balde Al, Han S, Cai Z, Li Z. A Retrospective Propensity Score Matched Study of the Preoperative C-Reactive Protein to Albumin Ratio and Prognosis in Patients with Resectable Non-Metastatic Breast Cancer. Med Sci Monit. 2019;25:4342-4352. doi: 10.12659/MSM.913684.

33. Wu MT, He SY, Chen SL, Li LF, He ZQ, Zhu YY, He X, Chen H. Clinical and prognostic implications of pretreatment albumin to C-reactive protein ratio in patients with hepatocellular carcinoma. BMC Cancer. 2019;19:538. doi: 10.1186/s12885-019-5747-5.

34. Wang F, Li P, Li FS. Prognostic role of C-reactive protein to albumin ratio in colorectal cancer: A meta analysis. Medicine (Baltimore). 2019;98(29):e16064. doi: 10.1097/MD.0000000000016064.

35. Jaffe ES, Harris NL, Stein H, Isaacson PG. Classification of lymphoid neoplasms: the microscope as a tool for disease discovery. Blood. 2008;112(12):4384-4399. doi: 10.1182/blood-2008-07-077982.

36. Swerdlow SH, Campo E, Pileri SA, Harris NL, Stein H, Siebert R, Advani R, Ghielmini M, Salles GA, Zelenetz AD, et al. The 2016 revision of the World Health Organization classification of lymphoid neoplasms. Blood. 2016;127(20):2375-2390. doi: 10.1182/blood-2016-01-643569.

37. Vittinghoff E, McCulloch CE. Relaxing the rule of ten events per variable in logistic and Cox regression. Am J Epidemiol. 2007;165(6):710-718. doi: 10.1093/aje/kwk052.

38. Landskron G, De la Fuente M, Thuwajit P, Thuwajit C, Hermoso MA. Chronic inflammation and cytokines in the tumor microenvironment. J Immunol Res. 2014;2014:149185. doi: 10.1155/2014/149185.

39. Chen S, Zambetti NA, Bindels EM, Kenswill K, Mylona AM, Adisty NM, Hoogenboezem RM, Sanders MA, Cremers EM, Westers TM, et al. Massive parallel RNA sequencing of highly purified mesenchymal elements in low-risk MDS reveals tissue-context-dependent activation of inflammatory programs. Leukemia. 2016;30(9):1938-1942. doi: 10.1038/leu.2016.91.

40. Sun Z, Wang S, Zhao RC. The roles of mesenchymal stem cells in tumor inflammatory microenvironment. J Hematol Oncol. $2014 ; 7: 14$. doi: 10.1186/1756-8722-7-14

41. Thanan R, Oikawa S, Yongvanit P, Hiraku Y, Ma N, Pinlaor S, Pairojkul C, Wongkham C, Sripa B, Khuntikeo N, et al. Inflammation-induced protein carbonylation contributes to poor prognosis for cholangiocarcinoma. Free Radic Biol Med. 2012;52(8):1465-1472. doi: 10.1016/j.freeradbiomed.2012.01.018.

42. Thanan R, Pairojkul C, Pinlaor S, Khuntikeo N, Wongkham C, Sripa B, Ma N, Vaeteewoottacharn K, Furukawa A, Kobayashi H, et al. Inflammation-related DNA damage and expression of CD133 and Oct3/4 in cholangiocarcinoma patients with poor prognosis. Free Radic Biol Med. 2013;65:1464-1472. doi: 10.1016/j.freeradbiomed.2013.07.034. 
43. Yang LY, Luo Q, Lu L, Zhu WW, Sun HT, Wei R, Lin ZF, Wang XY, Wang CQ, Lu M, et al. Increased neutrophil extracellular traps promote metastasis potential of hepatocellular carcinoma via provoking tumorous inflammatory response. J Hematol Oncol. 2020;13(1):3. doi: 10.1186/s13045-019-0836-0.

44. Yao X, Huang J, Zhong H, Shen N, Faggioni R, Fung M, Yao Y. Targeting interleukin- 6 in inflammatory autoimmune diseases and cancers. Pharmacol Ther. 2014;141(2):125-139. doi: 10.1016/j.pharmthera.2013.09.004.

45. Braconi C, Patel T. Cholangiocarcinoma: new insights into disease pathogenesis and biology. Infect Dis Clin N Am. 2010;24(4):871-884. doi: 10.1016/j.idc.2010.07.006.

46. Liu G, Zhang J, Frey L, Gang X, Wu K, Liu Q, Lilly M, Wu J. Prostate-specific IL-6 transgene autonomously induce prostate neoplasm through amplifying inflammation in the prostate and peri-prostatic adipose tissue. J Hematol Oncol. 2017;10(1):14. doi: 10.1186/s13045-016-0386-7.

47. Rosean TR, Tompkins VS, Olivier AK, Sompallae R, Norian LA, Morse HC 3rd, Waldschmidt TJ, Janz S. The tumor microenvironment is the main source of IL-6 for plasma cell tumor development in mice. Leukemia. 2015;29(1):233-237. doi: 10.1038/leu.2014.260.

48. Yang J, Wezeman M, Zhang X, Lin P, Wang M, Qian J, Wan B, Kwak LW, Yu L, Yi Q. Human C-reactive protein binds activating Fcgamma receptors and protects myeloma tumor cells from apoptosis. Cancer Cell. 2007;12(3):252-265. doi: 10.1016/j.ccr.2007.08.008.

49. Xu S, Li X, Liu Y, Xia Y, Chang R, Zhang C. Inflammasome inhibitors: promising therapeutic approaches against cancer. J Hematol Oncol. 2019;12(1):64. doi: 10.1186/s13045-019-0755-0.

50. Fairclough E, Cairns E, Hamilton J, Kelly C. Evaluation of a modified early warning system for acute medical admissions and comparison with C-reactive protein/albumin ratio as a predictor of patient outcome. Clin Med (Lond). 2009;9(1):30-33. doi: 10.7861/clinmedicine.9-1-30.

51. Chojkier M. Inhibition of albumin synthesis in chronic diseases: molecular mechanisms. J Clin Gastroenterol. 2005;39(4 Suppl 2):S143-146. doi: 10.1097/01.mcg.0000155514.17715.39.

\section{Tables}




\begin{tabular}{|c|c|c|c|c|c|c|c|c|c|c|}
\hline \multirow[t]{2}{*}{ Characteristics } & \multirow[t]{2}{*}{$\mathrm{N}(\%)$} & \multicolumn{2}{|c|}{$\begin{array}{l}\text { Pretreatment CRP } \\
\text { level, mg/L }\end{array}$} & \multicolumn{2}{|c|}{$\begin{array}{l}\text { Post-treatment } \\
\text { CRP level, mg/L }\end{array}$} & \multicolumn{3}{|c|}{ CRP kinetics, mg/L } & \multicolumn{2}{|l|}{ CAR } \\
\hline & & $\begin{array}{l}>5.84 \\
N(\%)\end{array}$ & $\begin{array}{l}p- \\
\text { value }\end{array}$ & $\begin{array}{l}>5.84 \\
\mathrm{~N}(\%)\end{array}$ & $\begin{array}{l}p- \\
\text { value }\end{array}$ & $\begin{array}{l}\text { ever }>5.84 \\
N(\%)\end{array}$ & $\begin{array}{l}\text { Continuously } \\
>5.84\end{array}$ & $\begin{array}{l}p- \\
\text { value }\end{array}$ & $\begin{array}{l}>0.117 \\
\mathrm{~N}(\%)\end{array}$ & $\begin{array}{l}p- \\
\text { value }\end{array}$ \\
\hline Female & $110(45.3 \%)$ & $28(27.7 \%)$ & 0.323 & $10(34.5 \%)$ & 0.445 & $31(28.2 \%)$ & $15(13.6 \%)$ & 0.135 & $35(34.7 \%)$ & 0.756 \\
\hline Male & $133(54.7 \%)$ & $41(33.9 \%)$ & & $9(25.7 \%)$ & & $42(31.6 \%)$ & $29(21.8 \%)$ & & $44(36.7 \%)$ & \\
\hline Age<60years & $131(53.9 \%)$ & $31(26.1 \%)$ & 0.082 & $6(17.6 \%)$ & 0.025 & $42(32.1 \%)$ & $15(11.5 \%)$ & 0.014 & $38(31.9 \%)$ & 0.201 \\
\hline >=60years & $112(46.1 \%)$ & $38(36.9 \%)$ & & $13(43.3 \%)$ & & $31(27.7 \%)$ & $29(25.9 \%)$ & & $41(40.2 \%)$ & \\
\hline $\begin{array}{l}\text { Clinical stage I-II } \\
\text { (0-II for CLL/ SLL) }\end{array}$ & $69(28.4 \%)$ & $10(15.6 \%)$ & 0.002 & 2(333.3\%) & 1.000 & $6(8.7 \%)$ & $11(15.9 \%)$ & $<0.001$ & $13(20.3 \%)$ & 0.002 \\
\hline III-IV & $174(71.6 \%)$ & $59(37.3 \%)$ & & $17(29.3 \%)$ & & $67(38.5 \%)$ & $33(19.0 \%)$ & & $66(42.0 \%)$ & \\
\hline $\mathrm{Hb}>=120 \mathrm{~g} / \mathrm{L}$ & $143(58.8 \%)$ & $22(16.4 \%)$ & $<0.001$ & $6(16.2 \%)$ & 0.006 & $39(27.3 \%)$ & $15(10.5 \%)$ & $<0.001$ & $25(18.7 \%)$ & $<0.001$ \\
\hline$<120 \mathrm{~g} / \mathrm{L}$ & $100(41.2 \%)$ & $47(53.4 \%)$ & & $13(48.1 \%)$ & & $34(34.0 \%)$ & $29(29.0 \%)$ & & $54(62.1 \%)$ & \\
\hline $\mathrm{PLT}>=100 * 10^{\wedge} 9 / \mathrm{L}$ & 203(83.5\%) & $56(29.9 \%)$ & 0.399 & $14(25.9 \%)$ & 0.249 & $60(29.6 \%)$ & $35(17.2 \%)$ & 0.594 & $64(34.4 \%)$ & 0.339 \\
\hline$<100 * 10^{\wedge} 9 / \mathrm{L}$ & $40(16.5 \%)$ & $13(37.1 \%)$ & & $5(50.0 \%)$ & & $13(32.5 \%)$ & $9(22.5 \%)$ & & $15(42.9 \%)$ & \\
\hline $\mathrm{LDH}<=250 \mathrm{U} / \mathrm{L}$ & 177(72.8\%) & $45(27.3 \%)$ & 0.045 & $15(33.3 \%)$ & 0.455 & $48(21.7 \%)$ & $31(17.5 \%)$ & 0.084 & $53(32.3 \%)$ & 0.117 \\
\hline$>250 U / L$ & $54(22.2 \%)$ & $20(42.6 \%)$ & & $4(23.5 \%)$ & & $23(42.6 \%)$ & $9(16.7 \%)$ & & $21(44.7 \%)$ & \\
\hline$\beta 2-M G<=3 \mathrm{mg} / \mathrm{L}$ & $133(54.7 \%)$ & $18(15.1 \%)$ & $<0.001$ & $10(28.6 \%)$ & 0.759 & $37(27.8 \%)$ & $12(9.0 \%)$ & $<0.001$ & $21(17.6 \%)$ & $<0.001$ \\
\hline$>3 \mathrm{mg} / \mathrm{L}$ & $109(44.9 \%)$ & $51(50.0 \%)$ & & $9(32.1 \%)$ & & $36(33.0 \%)$ & $32(29.4 \%)$ & & $57(56.4 \%)$ & \\
\hline Disease & & & $<0.001$ & & 0.038 & & & $<0.001$ & & $<0.001$ \\
\hline $\mathrm{FL}$ & 77(31.7\%) & $15(20.5 \%)$ & & $5(16.1 \%)$ & & $31(40.3 \%)$ & $7(9.1 \%)$ & & $19(26.0 \%)$ & \\
\hline MZL & $46(18.9 \%)$ & $15(33.3 \%)$ & & $3(33.3 \%)$ & & $16(34.8 \%)$ & $8(17.4 \%)$ & & 15(33.3\%) & \\
\hline CLL/SLL & $91(37.4 \%)$ & $20(26.3 \%)$ & & $5(33.3 \%)$ & & $17(18.7 \%)$ & $17(18.7 \%)$ & & $23(30.3 \%)$ & \\
\hline LPL/WM & $29(11.9 \%)$ & $19(67.9 \%)$ & & $6(66.7 \%)$ & & $9(30.0 \%)$ & $12(41.4 \%)$ & & $22(81.5 \%)$ & \\
\hline Hypertension & $56(23.0 \%)$ & 17(33.3\%) & 0.629 & $4(33.3 \%)$ & 1.000 & $18(32.1 \%)$ & $11(19.6 \%)$ & 0.841 & $19(37.3 \%)$ & 0.798 \\
\hline Diabetes & $21(8.6 \%)$ & $6(33.3 \%)$ & 0.829 & $4(57.1 \%)$ & 0.184 & $9(42.9 \%)$ & $4(19.0 \%)$ & 0.358 & $10(55.6 \%)$ & 0.067 \\
\hline $\begin{array}{l}\text { Cardiovascular } \\
\text { disease }\end{array}$ & $17(7.0 \%)$ & $7(43.8 \%)$ & 0.392 & $1(50.0 \%)$ & 0.516 & $3(17.6 \%)$ & $7(41.2 \%)$ & 0.063 & $7(43.8 \%)$ & 0.488 \\
\hline HBV infection & $15(6.2 \%)$ & $5(35.7 \%)$ & 0.929 & $2(50.0 \%)$ & 0.578 & $8(53.3 \%)$ & $2(13.3 \%)$ & 0.153 & $5(35.7 \%)$ & 0.998 \\
\hline IPI & & & 0.001 & & 0.986 & & & $<0.001$ & & $<0.001$ \\
\hline Low-risk & $78(32.1 \%)$ & $13(19.7 \%)$ & & $5(29.4 \%)$ & & $13(16.7 \%)$ & $9(11.5 \%)$ & & $15(22.7 \%)$ & \\
\hline Middle-risk & $104(42.8 \%)$ & $27(27.3 \%)$ & & $8(30.8 \%)$ & & $38(36.5 \%)$ & $15(14.4 \%)$ & & $31(31.3 \%)$ & \\
\hline High-risk & $61(25.1 \%)$ & $29(50.9 \%)$ & & $6(28.6 \%)$ & & $22(36.1 \%)$ & $20(32.8 \%)$ & & $33(58.9 \%)$ & \\
\hline Treatment plan & & & 0.001 & & 0.282 & & & $<0.001$ & & 0.007 \\
\hline $\begin{array}{l}\text { Non- } \\
\text { chemotherapy }\end{array}$ & $56(23.0 \%)$ & $8(14.3 \%)$ & & - & & $1(1.8 \%)$ & $7(12.5 \%)$ & & $11(19.6 \%)$ & \\
\hline $\begin{array}{l}\text { R-CHOP or CHOP- } \\
\text { like }\end{array}$ & $102(42.0 \%)$ & $31(32.0 \%)$ & & 10(23.3\%) & & $51(50.0 \%)$ & $12(11.8 \%)$ & & $35(36.1 \%)$ & \\
\hline R-FC or FC-like & $32(13.2 \%)$ & $7(38.9 \%)$ & & $5(41.7 \%)$ & & $13(40.6 \%)$ & $6(18.8 \%)$ & & $7(38.9 \%)$ & \\
\hline Ibrutinib & $9(3.7 \%)$ & $1(11.1 \%)$ & & - & & $1(11.1 \%)$ & $1(11.1 \%)$ & & $3(33.3 \%)$ & \\
\hline $\begin{array}{l}\text { Other } \\
\text { chemotherapy }\end{array}$ & $24(9.9 \%)$ & $13(59.1 \%)$ & & $4(50.0 \%)$ & & $7(29.2 \%)$ & $9(37.5 \%)$ & & $14(66.7 \%)$ & \\
\hline Untreated & $20(8.2 \%)$ & $9(45.0 \%)$ & & - & & $0(0.0 \%)$ & $9(45.0 \%)$ & & $9(45.0 \%)$ & \\
\hline
\end{tabular}


$C R P$ C-reactive protein, $C A R$ C-reactive protein to albumin ratio, $H b$ hemoglobin, $P L T$ platelet count, $L D H$ lactate dehydrogenase, $\beta 2-M G \beta 2$ microglobulin, FL follicular lymphoma, $C L L / S L L$ chronic lymphocytic leukemia/ small lymphocytic lymphoma, $M Z L$ marginal zone lymphoma, $L P L / W M$ lymphoplasmacytic lymphoma/ Waldenstroms macroglobulinemia, $H B V$ hepatitis $\mathrm{B}$ virus, IP/international prognostic index, $R$ - $C H O P$ rituximab, cyclophosphamide, doxorubicin, vincristine, and prednisone, $R-F C$ rituximab, fludarabine and cyclophosphamide.

\begin{tabular}{|c|c|c|c|c|c|c|}
\hline & OS & & DFS & & PFS & \\
\hline & $\mathrm{HR}(95 \% \mathrm{Cl})$ & $p$-value & $\mathrm{HR}(95 \% \mathrm{Cl})$ & $p$-value & $\mathrm{HR}(95 \% \mathrm{Cl})$ & $p$-value \\
\hline \multicolumn{7}{|l|}{ Univariate analyses } \\
\hline Elevated pretreatment CRP level & $6.546(2.543,16.853)$ & $<0.001$ & $4.704(2.305,9.601)$ & $<0.001$ & $3.177(1.694,5.961)$ & $<0.001$ \\
\hline Age $>=60$ years & $1.502(0.649,3.480)$ & 0.342 & $1.439(0.724,2.858)$ & 0.299 & $1.147(0.616,2.314)$ & 0.666 \\
\hline Clinical stage III and IV & $10.230(1.374,76.183)$ & 0.023 & $4.924(1.499,16.177)$ & 0.009 & $2.472(1.088,5.621)$ & 0.031 \\
\hline $\mathrm{Hb}<120 \mathrm{~g} / \mathrm{L}$ & $3.798(1.545,9.335)$ & 0.004 & $3.010(1.478,6.128)$ & 0.002 & $1.911(1.024,3.565)$ & 0.042 \\
\hline PLT $<100 * 10^{\wedge} 9 / \mathrm{L}$ & $5.390(2.327,12.485)$ & $<0.001$ & $3.129(1.516,6.458)$ & 0.002 & $2.409(1.198,4.841)$ & 0.014 \\
\hline $\mathrm{LDH}>250 \mathrm{U} / \mathrm{L}$ & $2.495(1.029,6.049)$ & 0.043 & $2.044(0.962,4.344)$ & 0.063 & $1.857(0.915,3.768)$ & 0.087 \\
\hline$\beta 2-M G>3 m g / L$ & $5.544(1.876,16.383)$ & 0.002 & $4.021(1.812,8.922)$ & 0.001 & $2.922(1.479,5.773)$ & 0.002 \\
\hline Disease type & $1.696(1.098,2.618)$ & 0.017 & $1.318(0.937,1.856)$ & 0.113 & $1.181(0.865,1.611)$ & 0.295 \\
\hline IPI & $2.211(1.221,4.004)$ & 0.009 & $1.909(1.192,3.059)$ & 0.007 & $1.598(1.041,2.453)$ & 0.032 \\
\hline Treatment plan & $1.820(1.434,2.312)$ & $<0.001$ & $1.478(1.226,1.781)$ & $<0.001$ & $1.367(1.151,1.624)$ & $<0.001$ \\
\hline \multicolumn{7}{|l|}{ Multivariate analyses } \\
\hline Elevated pretreatment CRP level & $5.110(1.904,13.717)$ & 0.001 & $3.767(1.777,7.984)$ & 0.001 & $2.606(1.338,5.076)$ & 0.005 \\
\hline Clinical stage III and IV & $3.469(0.435,27.698)$ & 0.241 & $2.275(0.651,7.955)$ & 0.198 & $1.425(0.587,3.458)$ & 0.434 \\
\hline PLT $<100 * 10^{\wedge} 9 / \mathrm{L}$ & $3.994(1.635,9.754)$ & 0.002 & $2.320(1.071,5.023)$ & 0.033 & $1.849(0.873,3.917)$ & 0.109 \\
\hline$\beta 2-M G>3 m g / L$ & $2.287(0.725,7.214)$ & 0.158 & $2.204(0.945,5.143)$ & 0.068 & $1.921(0.924,3.995)$ & 0.080 \\
\hline
\end{tabular}




\begin{tabular}{|c|c|c|c|c|}
\hline & OS & & DFS & \\
\hline & $\mathrm{HR}(95 \% \mathrm{Cl})$ & $p$-value & $\mathrm{HR}(95 \% \mathrm{Cl})$ & $p$-value \\
\hline \multicolumn{5}{|l|}{ Univariate analyses } \\
\hline Elevated post-treatment CRP level & $6.728(2.015,22.465)$ & 0.002 & $2.601(1.126,6.008)$ & 0.025 \\
\hline Age $>=60$ years & $1.880(0.886,3.987)$ & 0.100 & $1.583(0.862,2.906)$ & 0.138 \\
\hline Clinical stage III and IV & $3.102(1.072,8.976)$ & 0.037 & $3.157(1.324,7.530)$ & 0.010 \\
\hline $\mathrm{Hb}<120 \mathrm{~g} / \mathrm{L}$ & $3.212(1.490,6.926)$ & 0.003 & $2.578(1.394,4.768)$ & 0.003 \\
\hline PLT $<100 * 10^{\wedge} 9 / \mathrm{L}$ & $4.729(2.232,10.021)$ & $<0.001$ & $2.871(1.480,5.568)$ & 0.002 \\
\hline $\mathrm{LDH}>250 \mathrm{U} / \mathrm{L}$ & $2.971(1.386,6.368)$ & 0.005 & $2.161(1.119,4.172)$ & 0.022 \\
\hline$\beta 2-M G>3 m g / L$ & $3.478(1.538,7.866)$ & 0.003 & $2.953(1.553,5.615)$ & 0.001 \\
\hline Disease type & $1.646(1.107,2.449)$ & 0.014 & $1.265(0.928,1.723)$ & 0.136 \\
\hline IPI & $2.127(1.285,3.520)$ & 0.003 & $1.877(1.248,2.822)$ & 0.002 \\
\hline Treatment plan & $1.685(1.363,2.083)$ & $<0.001$ & $1.441(1.211,1.715)$ & $<0.001$ \\
\hline \multicolumn{5}{|l|}{ Multivariate analyses } \\
\hline Elevated post-treatment CRP level & $5.826(1.659,20.458)$ & 0.006 & $2.384(1.027,5.534)$ & 0.043 \\
\hline PLT $<100 * 10^{\wedge} 9 / \mathrm{L}$ & $8.532(2.065,35.241)$ & 0.003 & $2.727(0.997,7.455)$ & 0.051 \\
\hline$\beta 2-M G>3 m g / L$ & $1.474(0.382,5.682)$ & 0.573 & $1.648(0.672,4.043)$ & 0.275 \\
\hline
\end{tabular}




\begin{tabular}{|c|c|c|c|c|c|c|}
\hline & OS & & DFS & & PFS & \\
\hline & $\mathrm{HR}(95 \% \mathrm{Cl})$ & $p$-value & $\mathrm{HR}(95 \% \mathrm{Cl})$ & $p$-value & $\mathrm{HR}(95 \% \mathrm{Cl})$ & $p$-value \\
\hline \multicolumn{7}{|l|}{ Univariate analysis } \\
\hline Ever elevated CRP level & $1.763(0.661,4.707)$ & 0.257 & $3.483(1.615,7.511)$ & 0.001 & $2.638(1.346,5.173)$ & 0.005 \\
\hline Continuously elevated CRP level & $6.661(2.775,15.988)$ & $<0.001$ & $5.232(2.356,11.622)$ & $<0.001$ & $3.663(1.790,7.496)$ & $<0.001$ \\
\hline Age $>=60$ years & $2.316(1.096,4.893)$ & 0.028 & $1.724(0.946,3.142)$ & 0.075 & $1.259(0.726,2.184)$ & 0.412 \\
\hline Clinical stage III and IV & $3.463(1.205,9.950)$ & 0.021 & $3.664(1.534,8.750)$ & 0.003 & $2.180(1.0850,4.380)$ & 0.029 \\
\hline $\mathrm{Hb}<120 \mathrm{~g} / \mathrm{L}$ & $3.144(1.502,6.580)$ & 0.002 & $2.832(1.534,5.230)$ & 0.001 & $1.895(1.090,3.297)$ & 0.024 \\
\hline $\mathrm{PLT}<100 * 10^{\wedge} 9 / \mathrm{L}$ & $4.985(2.349,10.581)$ & $<0.001$ & $3.015(1.554,5.851)$ & 0.001 & $2.264(1.194,4.294)$ & 0.012 \\
\hline $\mathrm{LDH}>250 \mathrm{U} / \mathrm{L}$ & $2.316(1.107,4.845)$ & 0.026 & $2.220(1.172,4.206)$ & 0.014 & $2.074(1.128,3.816)$ & 0.019 \\
\hline$\beta 2-M G>3 m g / L$ & $4.224(1.862,9.580)$ & 0.001 & $3.153(1.670,5.953)$ & $<0.001$ & $2.354(1.324,4.186)$ & 0.004 \\
\hline Disease type & $1.602(1.093,2.348)$ & 0.016 & $1.290(0.956,1.741)$ & 0.095 & $1.173(0.885,1.554)$ & 0.268 \\
\hline IPI & $2.248(1.361,3.713)$ & 0.002 & $1.973(1.316,2.959)$ & 0.001 & $1.618(1.114,2.351)$ & 0.011 \\
\hline Treatment plan & $1.722(1.393,2.130)$ & $<0.001$ & $1.453(1.219,1.731)$ & $<0.001$ & $1.347(1.146,1.584)$ & $<0.001$ \\
\hline \multicolumn{7}{|l|}{ Multivariate analyses } \\
\hline Ever elevated CRP level & $1.149(0.422,3.128)$ & 0.785 & $2.425(1.105,5.322)$ & 0.027 & $2.086(1.040,4.188)$ & 0.039 \\
\hline Continuously elevated CRP level & $6.461(2.620,15.930)$ & $<0.001$ & $4.748(2.114,10.660)$ & $<0.001$ & $3.296(1.594,6.818)$ & 0.001 \\
\hline Clinical stage III and IV & $2.267(0.699,7.350)$ & 0.173 & $2.469(0.964,6.323)$ & 0.060 & $1.449(0.682,3.081)$ & 0.335 \\
\hline PLT $<100 * 10^{\wedge} 9 / \mathrm{L}$ & $4.025(1.791,9.049)$ & 0.001 & $1.984(0.977,4.028)$ & 0.058 & $1.633(0.816,3.271)$ & 0.166 \\
\hline$\beta 2-M G>3 m g / L$ & $2.392(0.960,5.962)$ & 0.061 & $2.100(1.036,4.255)$ & 0.039 & $1.791(0.963,3.331)$ & 0.065 \\
\hline
\end{tabular}




\begin{tabular}{|c|c|c|c|c|c|c|}
\hline & OS & & DFS & & PFS & \\
\hline & $\mathrm{HR}(95 \% \mathrm{Cl})$ & $p$-value & $\mathrm{HR}(95 \% \mathrm{Cl})$ & $p$-value & $\mathrm{HR}(95 \% \mathrm{Cl})$ & $p$-value \\
\hline \multicolumn{7}{|l|}{ Univariate analysis } \\
\hline Elevated CAR & $5.426(2.018,13.962)$ & $<0.001$ & $3.856(1.888,7.874)$ & $<0.001$ & $2.591(1.381,4.858)$ & 0.003 \\
\hline Age $>=60$ years & $1.513(0.653,3.503)$ & 0.334 & $1.446(0.728,2.874)$ & 0.292 & $1.259(0.726,2.184)$ & 0.412 \\
\hline Clinical stage III and IV & $10.102(1.356,75.237)$ & 0.024 & $4.844(1.474,15.918)$ & 0.009 & $2.180(1.085,4.380)$ & 0.029 \\
\hline $\mathrm{Hb}<120 \mathrm{~g} / \mathrm{L}$ & $3.828(1.558,9.408)$ & 0.003 & $3.029(1.488,6.167)$ & 0.002 & $1.895(1.090,3.297)$ & 0.024 \\
\hline PLT $<100 * 10^{\wedge} 9 / \mathrm{L}$ & $5.371(2.319,12.440)$ & $<0.001$ & $3.120(1.512,6.439)$ & 0.002 & $2.264(1.194,4.294)$ & 0.012 \\
\hline $\mathrm{LDH}>250 \mathrm{U} / \mathrm{L}$ & $2.484(1.024,6.023)$ & 0.044 & $2.036(0.958,4.329)$ & 0.065 & $2.074(1.128,3.816)$ & 0.019 \\
\hline$\beta 2-M G>3 m g / L$ & $5.583(1.889,16.498)$ & 0.002 & $4.043(1.822,8.970)$ & 0.001 & $2.354(1.324,4.186)$ & 0.004 \\
\hline Disease type & $1.711(1.106,2.646)$ & 0.016 & $1.326(0.941,1.868)$ & 0.107 & $1.173(0.885,1.554)$ & 0.268 \\
\hline IPI & $2.228(1.230,4.038)$ & 0.008 & $1.921(1.199,3.078)$ & 0.007 & $1.618(1.114,2.351)$ & 0.011 \\
\hline Treatment plan & $1.823(1.437,2.314)$ & $<0.001$ & $1.481(1.229,1.784)$ & $<0.001$ & $1.347(1.146,1.584)$ & $<0.001$ \\
\hline \multicolumn{7}{|l|}{ Multivariate analyses } \\
\hline Elevated CAR & $3.768(1.415,10.034)$ & 0.008 & $2.824(1.336,5.971)$ & 0.007 & $1.991(1.021,3.882)$ & 0.043 \\
\hline Clinical stage III and IV & $3.766(0.474,29.941)$ & 0.210 & $2.441(0.702,8.494)$ & 0.161 & $1.512(0.625,3.658)$ & 0.359 \\
\hline $\mathrm{PLT}<100 * 10^{\wedge} 9 / \mathrm{L}$ & $3.475(1.439,8.394)$ & 0.006 & $2.051(0.954,4.407)$ & 0.066 & $1.691(0.802,3.564)$ & 0.168 \\
\hline$\beta 2-M G>3 m g / L$ & $2.475(1.439,8.394)$ & 0.125 & $2.275(0.973,5.320)$ & 0.058 & $2.002(0.959,4.178)$ & 0.064 \\
\hline
\end{tabular}

\begin{tabular}{|c|c|c|c|c|c|c|c|c|c|c|c|}
\hline & \multicolumn{3}{|c|}{ Pretreatment CRP level } & \multicolumn{2}{|c|}{ Post-treatment CRP level } & \multicolumn{3}{|c|}{ CRP kinetics } & \multicolumn{3}{|l|}{ CAR } \\
\hline & os & DFS & PFS & os & DFS & os & DFS & PFS & os & DFS & PFS \\
\hline & $p$-value & $p$-value & $p$-value & $p$-value & $p$-value & $p$-value & $p$-value & $p$-value & $p$-value & $p$-value & $p$-value \\
\hline $\mathrm{FL}$ & 0.006 & $<0.001$ & 0.004 & 0.317 & 0.600 & 0.034 & 0.040 & 0.023 & 0.019 & 0.002 & 0.022 \\
\hline MZL & 0.488 & 0.515 & 0.579 & 0.075 & 0.937 & 0.355 & 0.168 & 0.181 & 0.488 & 0.515 & 0.579 \\
\hline CLL/SLL & $<0.001$ & $<0.001$ & $<0.001$ & 0.006 & 0.033 & $<0.001$ & $<0.001$ & 0.001 & 0.001 & $<0.001$ & $<0.001$ \\
\hline WM & 0.500 & 0.399 & 0.399 & 0.295 & 0.295 & 0.399 & 0.392 & 0.392 & 0.998 & 0.998 & 0.998 \\
\hline
\end{tabular}

\section{Figures}


Figure 1
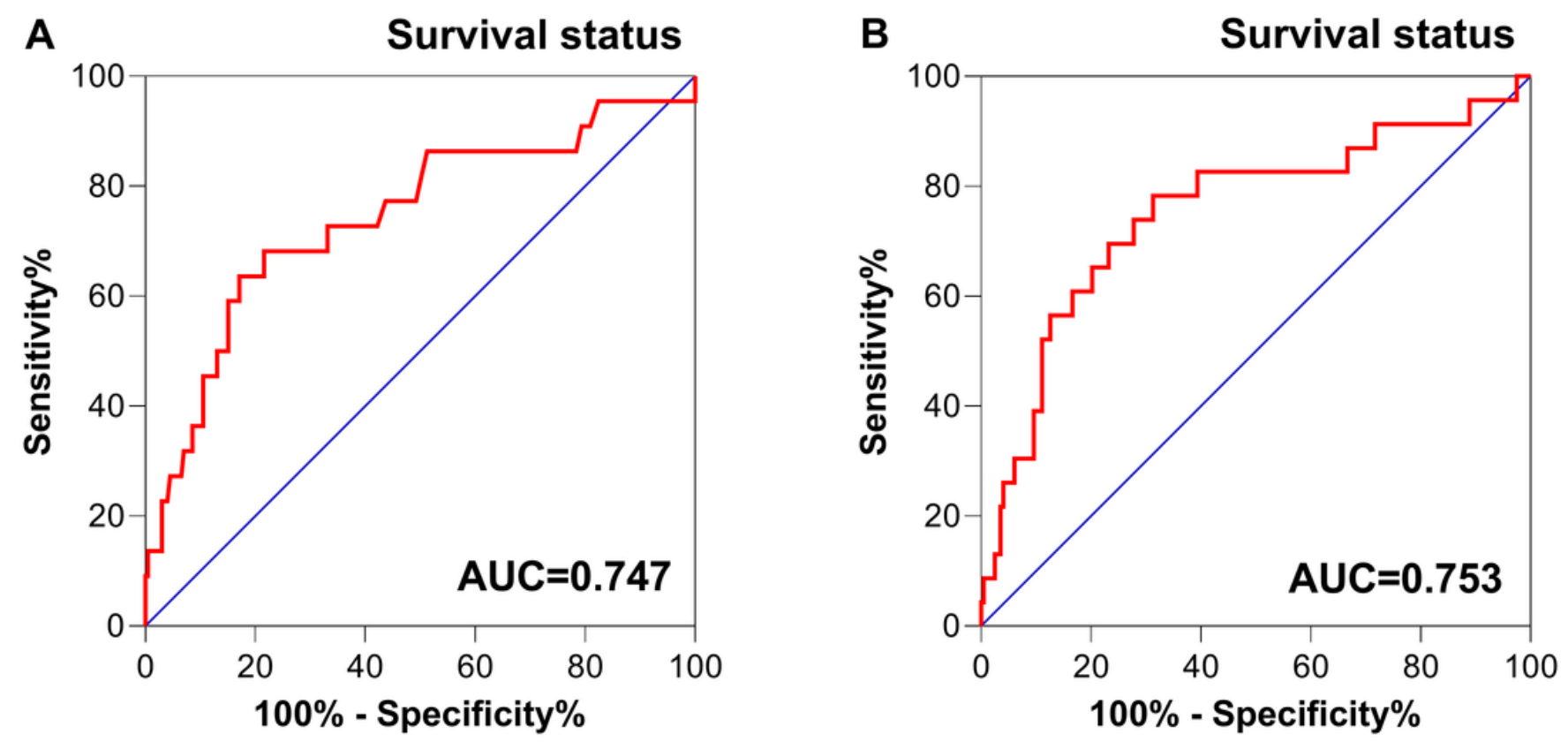

Figure 1

Receiver operating characteristic curve analysis determination of cutoff score. (A) For pretreatment serum C-reactive protein level. (B) For C-reactive protein to albumin ratio.

Figure 1
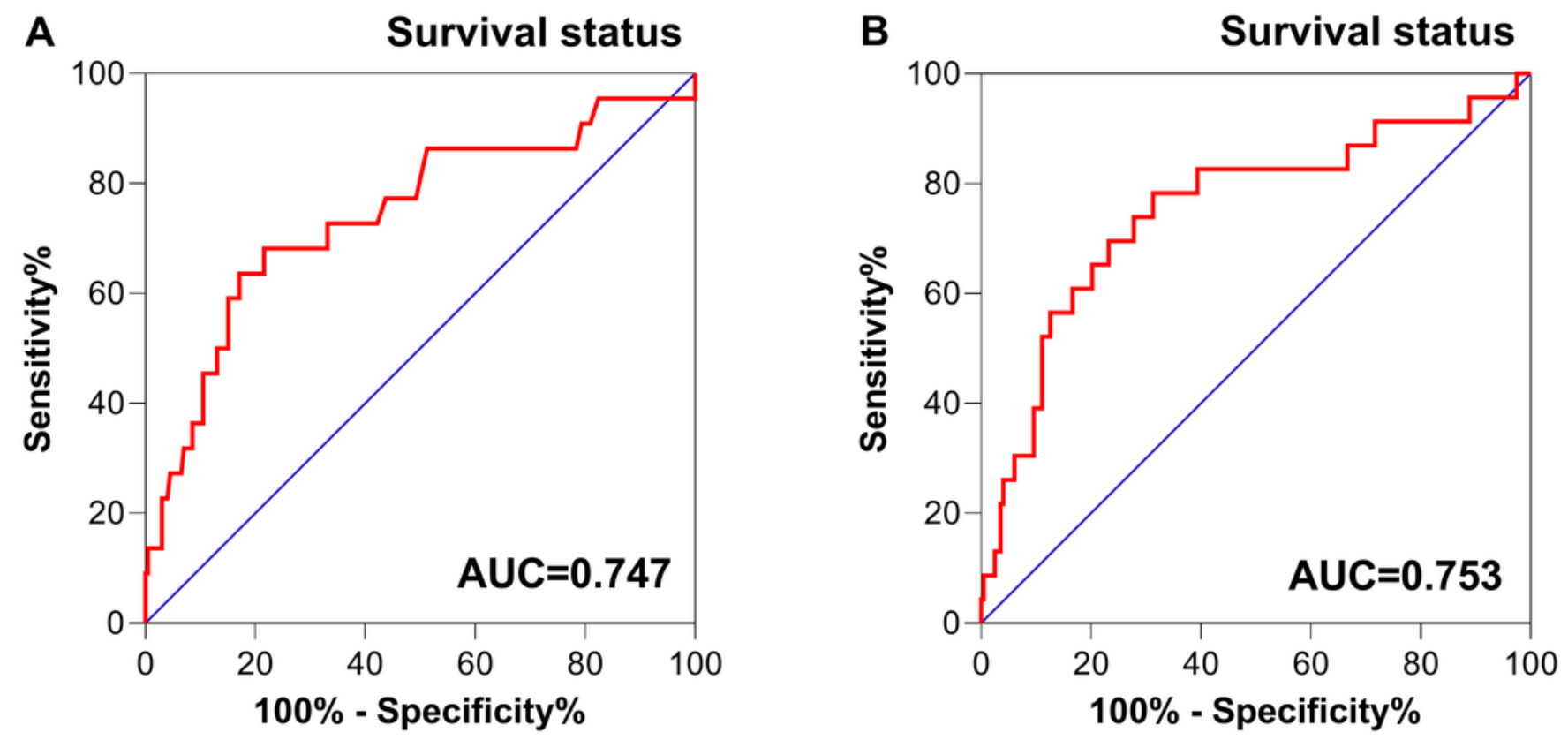

Figure 1

Receiver operating characteristic curve analysis determination of cutoff score. (A) For pretreatment serum C-reactive protein level. (B) For C-reactive protein to albumin ratio. 
Figure 2
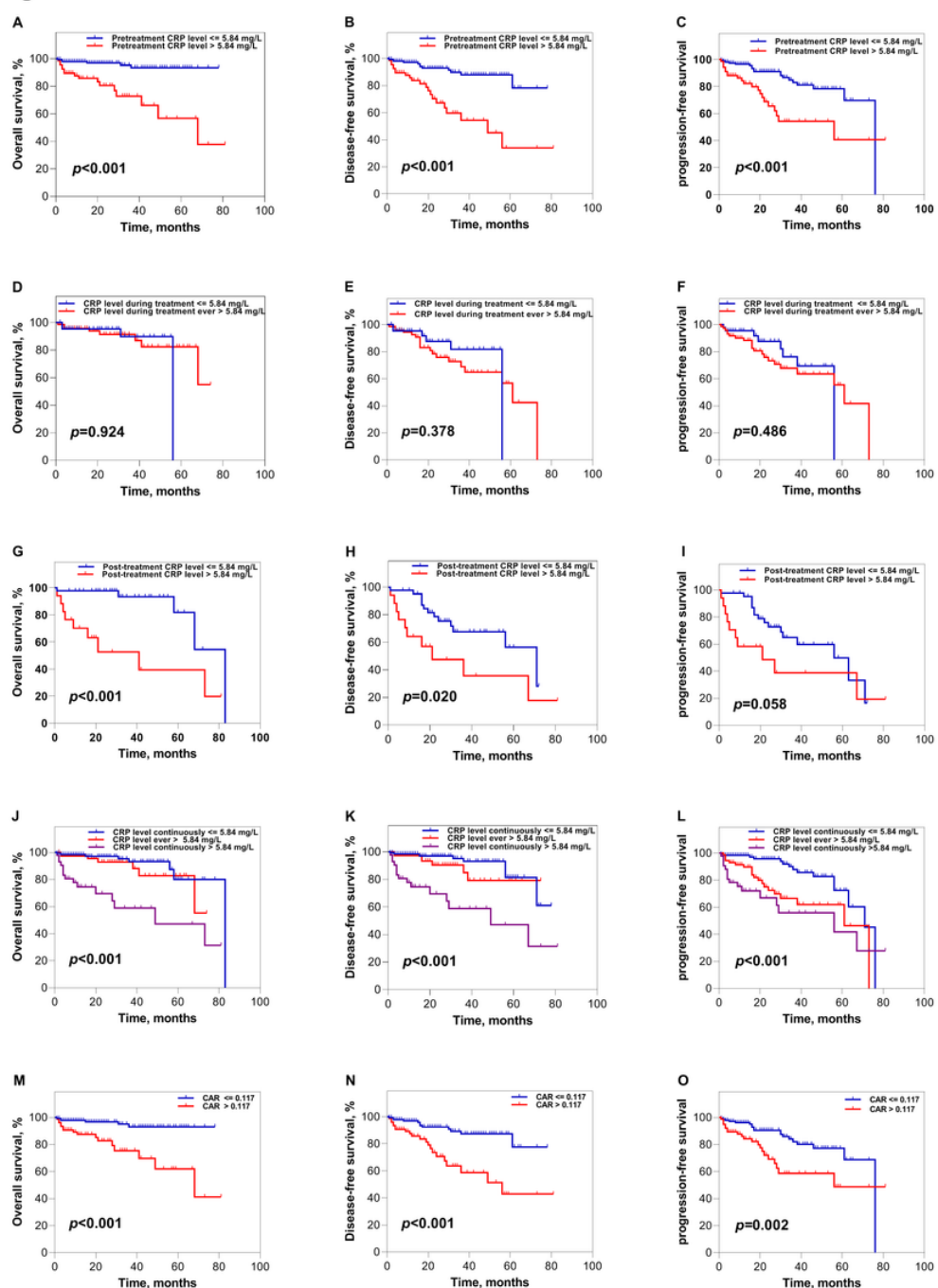

Figure 2

Kaplan-Meier analysis. (A) Overall survival according to pretreatment C-reactive protein level. (B) Disease-free survival according to pretreatment Creactive protein level. (C) Progression -free survival according to pretreatment C-reactive protein level. (D) Overall survival according to C-reactive protein level during treatment. (E) Disease-free survival according to C-reactive protein level during treatment. (F) Progression-free survival according to $\mathrm{C}$-reactive protein level during treatment. (G) Overall survival according to post-treatment C-reactive protein level. $(\mathrm{H})$ Disease-free survival according to post-treatment C-reactive protein level. (I) Progression-free survival according to post-treatment C-reactive protein level. (J) Overall survival according to C-reactive protein kinetics. (K) Disease-free survival according to C-reactive protein kinetics. (L) Progression -free survival according to C-reactive protein kinetics. (M) Overall survival according to C-reactive protein to albumin ratio. (N) Disease-free survival according to C-reactive protein to albumin ratio. (0) Progression-free survival according to C-reactive protein to albumin ratio. 
Figure 2
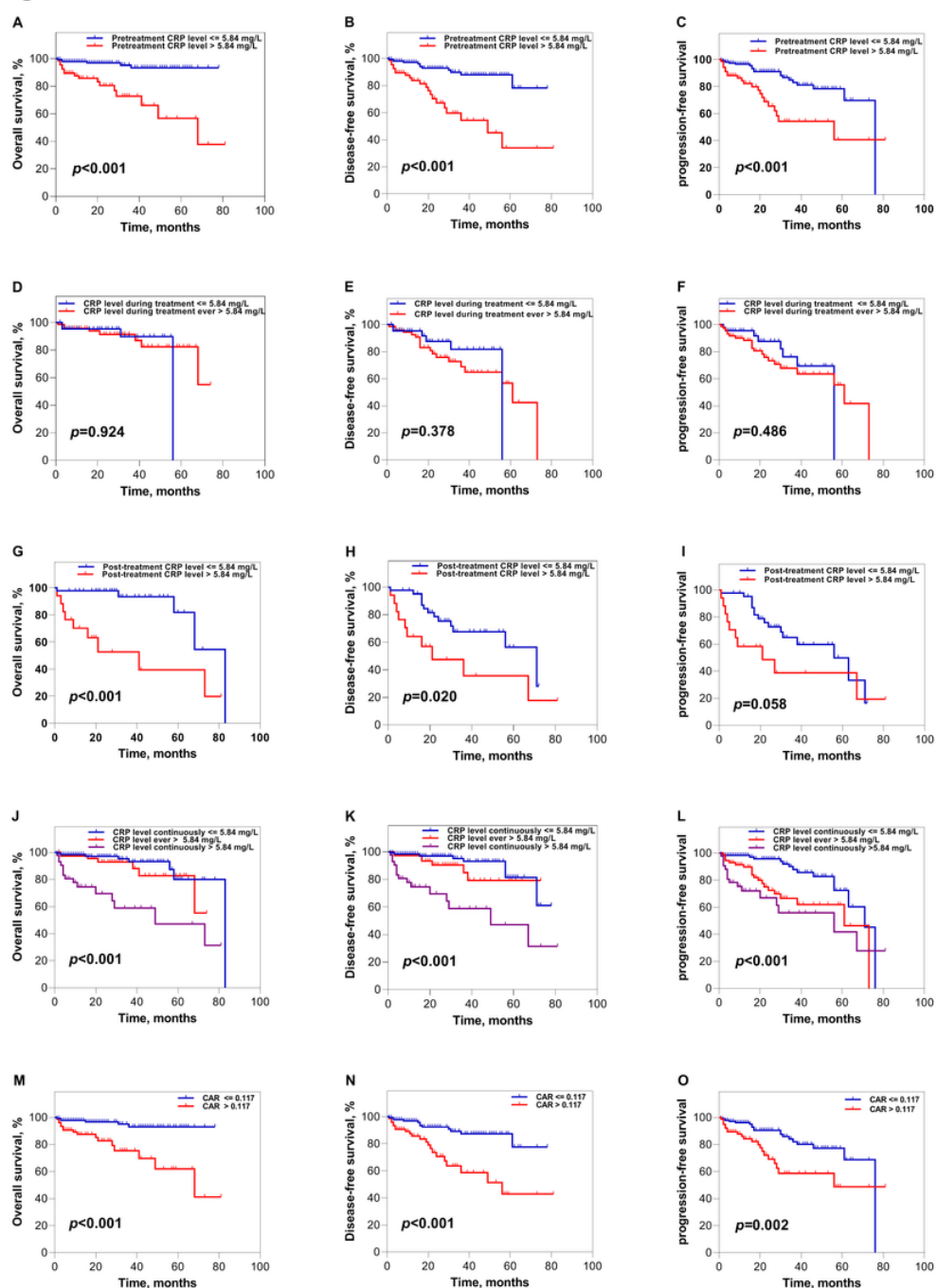

Figure 2

Kaplan-Meier analysis. (A) Overall survival according to pretreatment C-reactive protein level. (B) Disease-free survival according to pretreatment Creactive protein level. (C) Progression -free survival according to pretreatment C-reactive protein level. (D) Overall survival according to C-reactive protein level during treatment. (E) Disease-free survival according to C-reactive protein level during treatment. (F) Progression-free survival according to $\mathrm{C}$-reactive protein level during treatment. (G) Overall survival according to post-treatment C-reactive protein level. $(\mathrm{H})$ Disease-free survival according to post-treatment C-reactive protein level. (I) Progression-free survival according to post-treatment C-reactive protein level. (J) Overall survival according to C-reactive protein kinetics. (K) Disease-free survival according to C-reactive protein kinetics. (L) Progression -free survival according to C-reactive protein kinetics. (M) Overall survival according to C-reactive protein to albumin ratio. (N) Disease-free survival according to C-reactive protein to albumin ratio. (0) Progression-free survival according to C-reactive protein to albumin ratio. 